\title{
Article \\ Unveiling Semiconductor Nanostructured Based Holmium-Doped ZnO: Structural, Luminescent and Room Temperature Ferromagnetic Properties
}

\author{
Guy L. Kabongo ${ }^{1, *}$, Gugu H. Mhlongo ${ }^{2}$ (1) and Mokhotjwa S. Dhlamini ${ }^{1}$ \\ 1 Department of Physics, University of South Africa, P.O. Box 392, Pretoria 0003, South Africa; \\ dhlamms@unisa.ac.za \\ 2 CSIR-National Centre for Nano-Structured Materials, P.O. Box 395, Pretoria 0001, South Africa; \\ gmhlongo@csir.co.za \\ * Correspondence: geekale@gmail.com
}

check for updates

Citation: Kabongo, G.L.; Mhlongo, G.H.; Dhlamini, M.S. Unveiling Semiconductor Nanostructured Based Holmium-Doped ZnO: Structural, Luminescent and Room Temperature Ferromagnetic Properties. Nanomaterials 2021, 11 2611. https://doi.org/10.3390/ nano11102611

Academic Editors: Nikos Boukos, Protima Rauwel and Erwan Rauwel

Received: 27 July 2021

Accepted: 16 September 2021

Published: 4 October 2021

Publisher's Note: MDPI stays neutral with regard to jurisdictional claims in published maps and institutional affiliations.

Copyright: (c) 2021 by the authors. Licensee MDPI, Basel, Switzerland. This article is an open access article distributed under the terms and conditions of the Creative Commons Attribution (CC BY) license (https:// creativecommons.org/licenses/by/ $4.0 /)$.

\begin{abstract}
This research work describes the synthesis of $\mathrm{ZnO}$ nanostructures doped with $\mathrm{Ho}^{3+}$ ions using a conventional sol-gel synthesis method. The nanostructured produced exhibited a wurtzite hexagonal structure in both $\mathrm{ZnO}$ and $\mathrm{ZnO}: \mathrm{Ho}^{3+}(0.25,0.5,0.75 \mathrm{~mol} \%)$ samples. The change in morphology with addition of $\mathrm{Ho}^{3+}$ dopants was observed, which was assigned to Ostwald ripening effect occurring during the nanoparticles' growth. The photoluminescence emission properties of the doped samples revealed that $\mathrm{Ho}^{3+}$ was emitting through its electronic transitions. Moreover, reduced surface defects were observed in the Holmium doped samples whose analysis was undertaken using an X-ray Photoelectron Spectroscopy (XPS) technique. Finally, enhanced room temperature ferromagnetism (RT-FM) for $\mathrm{Ho}^{3+}$-doped $\mathrm{ZnO}(0.5 \mathrm{~mol} \%)$ samples with a peak-to-peak line width of $452 \mathrm{G}$ was detected and found to be highly correlated to the UV-VIS transmittance results.
\end{abstract}

Keywords: ZnO; holmium; nanostructures; ferromagnetism; XPS

\section{Introduction}

The surge of interest observed on $\mathrm{ZnO}$ nanostructures research in the past three decades among the scientific community was due to the versatile optical, magnetic and surface properties that they display under room temperature conditions [1]. The $\mathrm{ZnO}$ wide direct tunable band-gap, large exciton binding energy at room temperature makes it to be a convenient material for device fabrication in a wide range of applications such as optoelectronic, photonics and dilute magnetic semiconductors (DMS) [2-5]. It has potentialities to be applied in other devices such as gas sensors [6], biolabels [7], solar cells [8] and piezoelectric nanogenerators [9]. Recently, several research groups have investigated the optical properties of $\mathrm{ZnO}$ nanostructures exhibiting different morphologies such as flower-like [10], nanorods [11], comb-like [12] and nanowire arrays [13]. The need to engineer $\mathrm{ZnO}$ defects has driven scientists to dope this semiconductor material with either transition metal ions or light emitting elements such as the promising rare earth ions which in most cases resulted in tailoring the band-gap of $\mathrm{ZnO}$ [14]. Despite its large magnetic moment, $\mathrm{Ho}^{3+}$ has attracted less interest within the scientific community. Recently, Popa et al. [15] investigated the impact of structural on optical properties of sol-gel derived holmium doped $\mathrm{ZnO}$ thin films using relatively higher doping concentrations (1, $3,5$ at $\%)$, and others have demonstrated elsewhere that holmium concentration variation is very effective in tuning $\mathrm{ZnO}$ properties [16]. Earlier, Khataee and co-workers [17] reported on holmium doped zinc oxide nanoparticles synthesized via sonochemistry for the evaluation of the Reactive Orange 29 degradation in catalysis. Moreover, Singh and colleagues have successfully measured the DC magnetization and resistivity in Ho doped $\mathrm{ZnO}$ nanoparticles produced via wet chemical synthesis [18]. Furthermore, in their 
investigation dedicated to unveiling the optical and dielectric properties of Ho-doped $\mathrm{ZnO}$, a research group have successfully established the correlation of the abovementioned properties to $\mathrm{ZnO}$ related defects [19]. Interestingly, sol-gel remains to date one of the most efficient synthesis procedure to produce ultrasmallZnO nanoparticles [20,21]. In the current study, the observed change in morphology in $\mathrm{Ho}^{3+}$-doped $\mathrm{ZnO}$ nanocrystals is reported, and it was assigned to Ostwald ripening effect which occurred during the growth process of $\mathrm{ZnO}$ nanostructures. Moreover, a comparison of the defect state XPS core levels in un-doped and $\mathrm{Ho}^{3+}$-doped $\mathrm{ZnO}(0.5 \mathrm{~mol} \%)$ samples is presented and discussed in detail. Furthermore, in spite of the low concentration of $\mathrm{Ho}^{3+}$ dopant, XPS Ho $4 \mathrm{~d}$ core levels were detected. Finally, the current research work is a novel experimental study on room temperature ferromagnetism based on microwave absorption of $\mathrm{Ho}^{3+}$ ions doped in $\mathrm{ZnO}$ nanostructures owing to the large magnetic moment of $\mathrm{Ho}^{3+}$. The ferromagnetism enhancement observed which is related to the number of spins participating to the ferromagnetic resonance is found to be in accordance with the UV-VIS transmittance and band-gap results (Scheme 1).

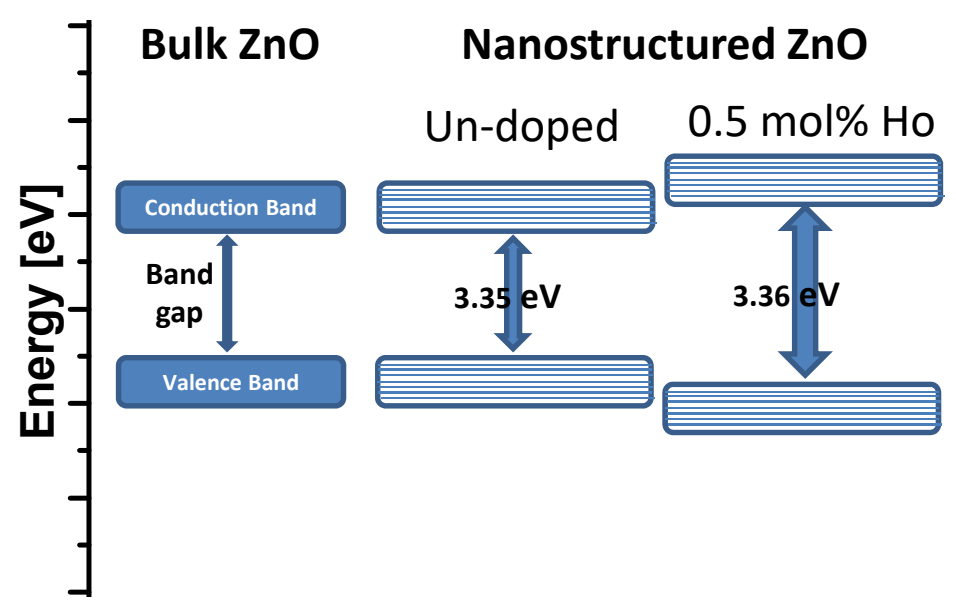

Scheme 1. ZnO Band-gap engineering.

\section{Experimental Section}

The samples used in the present study were all synthesized in the same conditions, except the molar concentration of Ho dopant which varied. The synthesis was conducted using zinc acetate $\left(\mathrm{Zn}\left(\mathrm{CH}_{3} \mathrm{COO}\right)_{2} \cdot 2 \mathrm{H}_{2} \mathrm{O}\right)$, sodium hydroxide $(\mathrm{NaOH})$ and holmium nitrate pentahydrate $\left(\mathrm{Ho}\left(\mathrm{NO}_{3}\right)_{3} \cdot 5 \mathrm{H}_{2} \mathrm{O}\right)$, which were all purchased from Sigma-Aldrich (Kempton

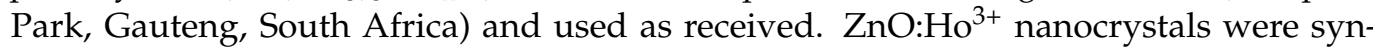
thesized by a sol-gel method following the same procedure as reported in our previous works [22-24]. The solution of sodium hydroxide dissolved in ethanol was prepared separately, then cooled in ice water and added dropwise judiciously to the ethanol solution of $\mathrm{Zn}^{2+}$ ions. For preparation of $\mathrm{Ho}^{3+}$-doped $\mathrm{ZnO}$ samples with different concentrations of $\mathrm{Ho}^{3+}(0.25,0.5$ and $0.75 \mathrm{~mol} \%)$, the ethanol solution of Holmium nitrate pentahydrate was added into the hydrolyzed $\mathrm{Zn}^{2+}$ solution prepared following the above route. The obtained clear solution was kept at room temperature for $24 \mathrm{~h}$ and then washed several times in a mixture of ethanol and heptane (1:2 molar ratio) to eliminate unreacted $\mathrm{Na}^{+}$and $\mathrm{CH}_{3} \mathrm{COO}^{-}$ions. The resulting precipitates were then re-dispersed in ethanol and dried at $200{ }^{\circ} \mathrm{C}$ for $2 \mathrm{~h}$ in an electric oven (ambient atmosphere).

The structure of the obtained samples was characterized on an X'Pert PRO PANalytical diffractometer with $\mathrm{CuK} \alpha$ at $\lambda=0.15405 \mathrm{~nm}$. Transmission electron microscopy (TEM) images were taken by using a JEOL-Jem2100 microscope. Morphology and chemical composition of the samples (Cu-grid deeped in ethanolic solution of the sample) were analyzed using a JEOL JSM-7500F field-emission scanning electron microscope (FE-SEM, JEOL Ltd.,Tokyo, Japan) equipped with energy dispersive X-ray spectrometer (EDX) (an Oxford Instruments, High Wycombe, UK). Photoluminescence (PL) and Time Resolved PL properties for the un-doped and doped samples were analyzed using a JobinYvonFluorolog 
3 spectrofluorometer equipped with a Xenon lamp and nanoLED for excitation at room temperature. The transmittance measurements were carried out using a Perkin-Elmer Lambda $1050 \mathrm{UV} /$ Vis/NIR spectrophotometer. The X-ray photoelectron spectroscopy (XPS) core levels were carried out using a PHI 5000 Versaprobe-Scanning ESCA Microprobe (ULVAC-PHI, Inc. Kanagawa, Japan). Finally, the room temperature magnetization measurements were examined through the microwave absorption measurements collected using a JEOL $X$-band electron spin resonance (ESR; JEOL Ltd.,Tokyo, Japan) spectrometer (JES FA 200; JEOL Ltd.,Tokyo, Japan) operating at 9.4 GHz equipped with an Oxford ESR900 gas-flow cryostat and a temperature controller (Scientific instruments 9700; Oxford Instruments plc, Abingdon, UK). In order to evade saturation during measurements, the microwave power was maintained at $5 \mathrm{~mW}$. The DC static field HDC was slowly swept between 0 and 8360 Gauss. The DC field was modulated with an AC field whose amplitude was kept constant at $100 \mathrm{kHz}$ frequency. The microwave absorption output was measured as a derivative signal.

\section{Results and Discussion}

\subsection{EDS, SEM, TEM, XRD Analysis}

Considering that during the course of experiment the photoluminescence optimization which revealed that optimum luminescence was obtained from $0.5 \mathrm{~mol} \% \mathrm{Ho}^{3+}$-doped $\mathrm{ZnO}$, particular attention was devoted to elucidating the microstructural behavior of $0.5 \mathrm{~mol} \%$ $\mathrm{Ho}^{3+}$-doped $\mathrm{ZnO}$ sample relative to the un-doped $\mathrm{ZnO}$. The elemental composition of the sample in Figure 1a was surveyed by EDS to demonstrate qualitatively the presence of holmium dopant in the investigated area of the sample in addition to zinc and oxygen. However, the observed copper peak originates from SEM sample preparation (i.e., $\mathrm{Cu}$ grid) [14]. It is worth mentioning that the expected chemical species were all found to be well distributed throughout the analyzed area (see Figure S1) of the as-synthesized sample as shown in Figure 1b. Figure 1c,d shows classical SEM micrographs for the un-doped and $0.5 \mathrm{~mol} \% \mathrm{Ho}^{3+}$-doped samples, respectively. The images show that spherical-like $\mathrm{ZnO}$ particles in the case of un-doped sample and rod-like particles in the case of $0.5 \mathrm{~mol} \%$ $\mathrm{Ho}^{3+}$-doped samples were formed during the wet chemical synthesis route. Interestingly, the observed mutation of particle morphology from un-doped to $0.5 \mathrm{~mol} \% \mathrm{Ho}^{3+}$-doped $\mathrm{ZnO}$ samples is attributed to the Ostwald ripening effect $[25,26]$.

TEM measurements were undertaken carefully on both un-doped and $0.5 \mathrm{~mol} \% \mathrm{Ho}^{3+}$ doped $\mathrm{ZnO}$ samples (see Figure 2). The measurements revealed that the nanostructures were evenly distributed and were highly crystalline. However, a peculiar phenomenon based on the mutation of morphology was observed and was attributed to doping with holmium ions, more precisely due to the growth of nanoparticles in solution through a diffusion limited Ostwald ripening process known to be the most predominantly growth mechanism so far [27]. However, further investigations are required in order to effectively elucidate on the observed mechanism of morphology mutation. It is however suggested that studies on colloidal nanocrystals growth under TEM using the so-called liquid cell electron microscopy $[28,29]$ should be performed. Such study has been undertaken previously but not quite intensively, especially on the $\mathrm{ZnO}$ nanoparticles growth [30]. TEM analysis revealed that the particles diameter and width were $\sim 10 \mathrm{~nm}$ for un-doped and $0.5 \mathrm{~mol} \% \mathrm{Ho}^{3+}$-doped $\mathrm{ZnO}$, respectively, the former contained a mixture of spherical like and rod-like particles. The TEM result is found to be consistent with former SEM particles morphology characterization. 
(a)
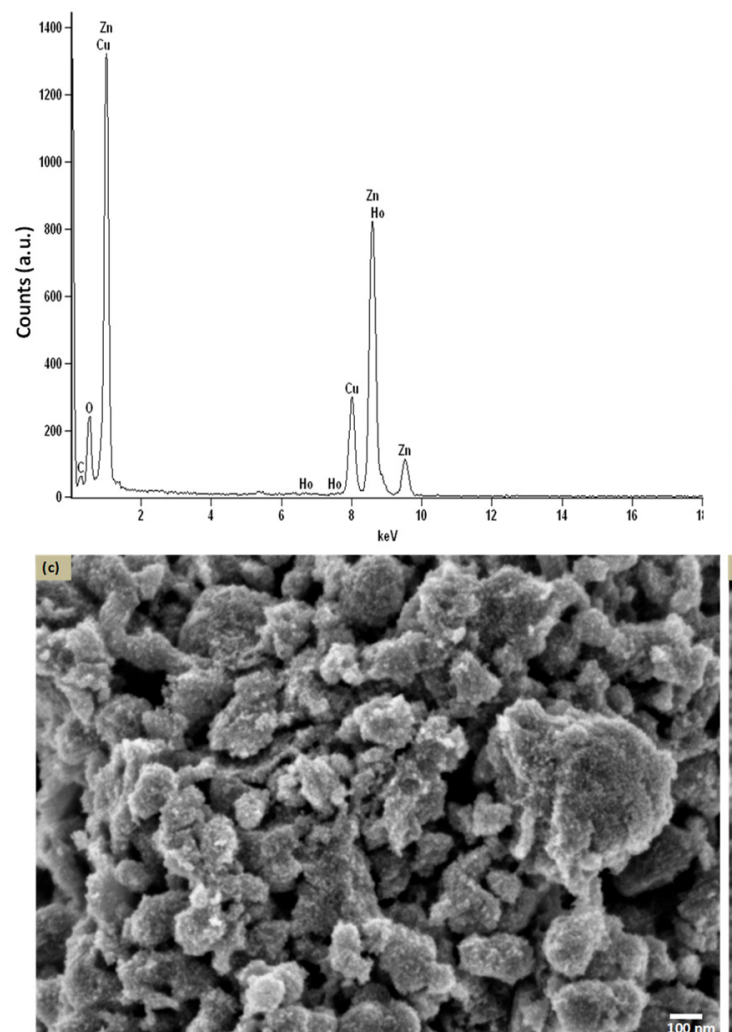

(b)
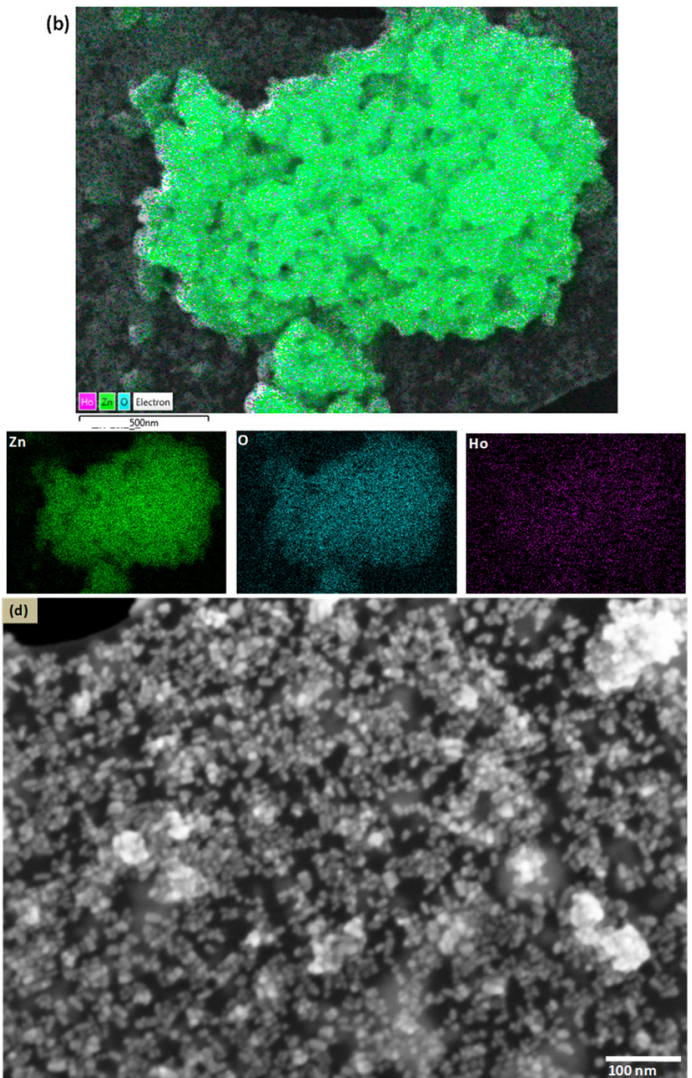

Figure 1. EDS (a) spectrum and (b) elemental mapping for $0.5 \mathrm{~mol} \% \mathrm{Ho}^{3+}$-doped $\mathrm{ZnO}$ nanocrystals. SEM micrographs for (c) un-doped $\mathrm{ZnO}$ and (d) $(0.5 \mathrm{~mol} \%) \mathrm{Ho}^{3+}$-doped $\mathrm{ZnO}$ nanocrystals.

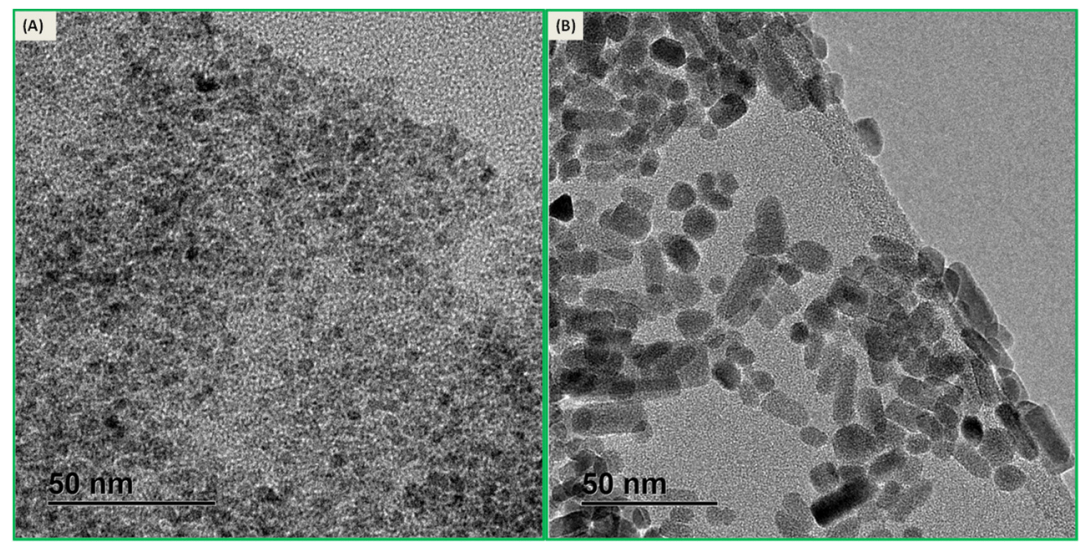

Figure 2. TEM images for (A) un-doped and (B) $(0.5 \mathrm{~mol} \%) \mathrm{Ho}^{3+}$-doped $\mathrm{ZnO}$ nanocrystals.

Figure 3 illustrates the X-ray diffraction (XRD) profiles of the $\mathrm{ZnO}$ and $\mathrm{ZnO}: \mathrm{Ho}^{3+}$ nanocrystals. The analysis revealed that the as-synthesized nanocrystals ranging between 4-8 $\mathrm{nm}$ in diameter (See Table 1) were highly crystalline and exhibited the hexagonal wurtzite structure (space group $\mathrm{P}_{3} m c$ ) indexed to JCPDS card \# 36-1451. Furthermore, no second phase originating from $\mathrm{Ho}_{2} \mathrm{O}_{3}$ was observed in the $\mathrm{Ho}^{3+}$-doped $\mathrm{ZnO}$ samples [31], which confirms that the dopants successfully substituted the $\mathrm{Zn}^{2+}$ ions within the $\mathrm{ZnO}$ lattice structure. The Scherrer equation was employed to estimate the crystallite size [32];

$$
D=\frac{k \lambda}{\beta \cos O}
$$


where $D, \lambda, \beta$, $\Theta$ and $k$ are the crystallite size, the wavelength of the incident $\mathrm{X}$-ray CuK radiation $(0.15405 \mathrm{~nm})$, the full width at half maximum (FWHM), the diffracting angle and a numerical constant (0.89), respectively. The results obtained are consistent with the TEM results, where the particles were in the nanometer range (see Figure S2).

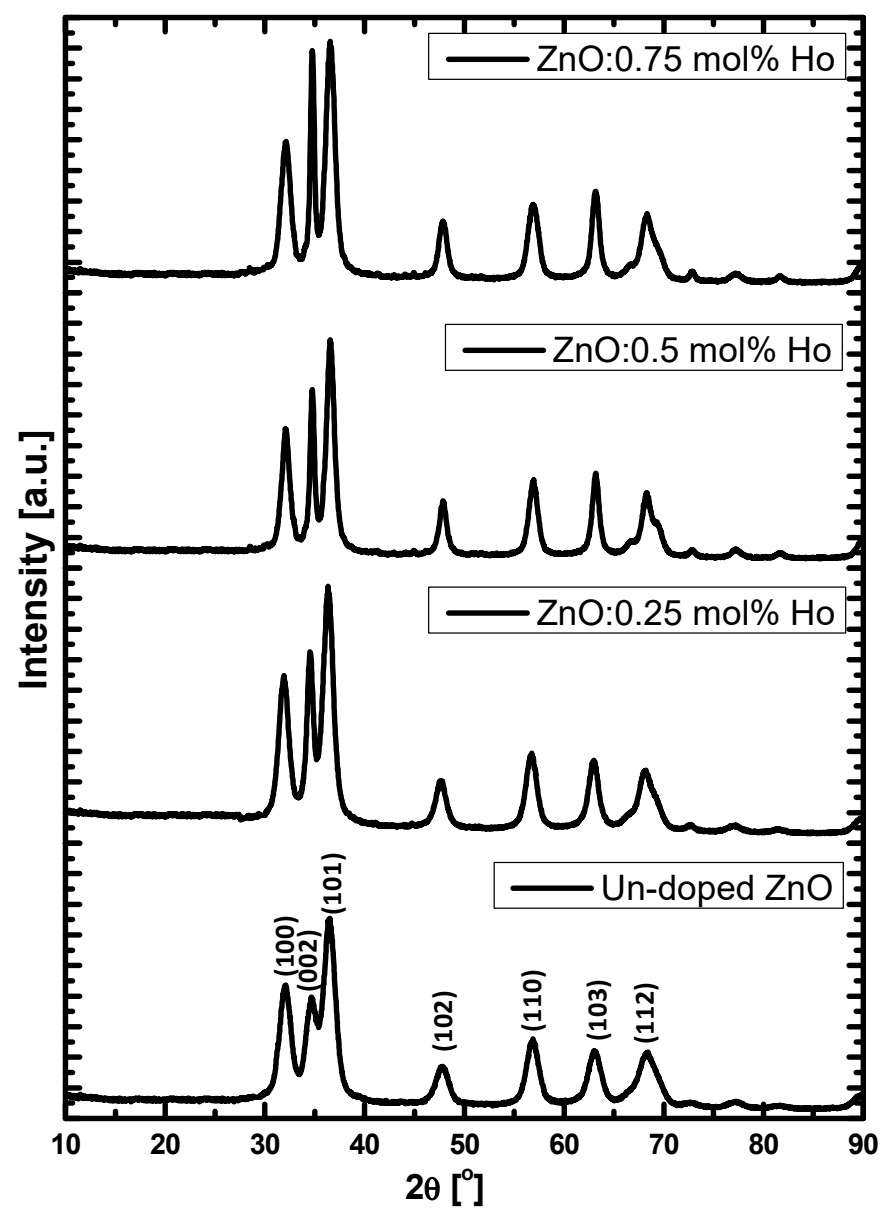

Figure 3. XRD patterns for undopedZnO and $\mathrm{Ho}^{3+}$-doped $\mathrm{ZnO}$ nanocrystals dried at $200{ }^{\circ} \mathrm{C}$.

Table 1. The XRD parameters and the average estimated crystallite size (D) from Scherrer equation.

\begin{tabular}{cccc}
\hline Sample & $\begin{array}{c}\mathbf{2 \theta ( 1 0 1 )} \\
\text { [Degrees] }\end{array}$ & $\boldsymbol{\Delta ( 2 \theta )}[$ Rad] FWHM $=\boldsymbol{\beta}$ & $\begin{array}{c}\mathbf{D} \\
\text { [nm] }\end{array}$ \\
\hline Un-doped ZnO & 36.52 & 0.02913 & 5.0 \\
$0.25 \mathrm{~mol} \% \mathrm{Ho}$ & 36.34 & 0.02234 & 6.5 \\
$0.5 \mathrm{~mol} \% \mathrm{Ho}$ & 36.55 & 0.01768 & 8.2 \\
$0.75 \mathrm{~mol} \% \mathrm{Ho}$ & 36.55 & 0.02042 & 7.1 \\
\hline
\end{tabular}

3.2. UV-VISTransmittance and Photoluminescence for Undoped and $\mathrm{Ho}^{3+}$-Doped $\mathrm{ZnO}$ Nanostructures

The transmittance spectra in the range of 300-700 nm are depicted on Figure 4a. A sharp UV cut off band at approximately $360 \mathrm{~nm}$ was observed and assigned to the band-toband transition of $\mathrm{ZnO}$. The bandedge peak is found to be highly blue shifted as compared to the bulk $\mathrm{ZnO}(\sim 386 \mathrm{~nm})$ [33] owing to quantum confinement effect [34]. The un-doped $\mathrm{ZnO}$ sample exhibited a transmittance of the order of $40 \%$ far below the $0.5 \mathrm{~mol} \% \mathrm{Ho}^{3+}$ tramittance which is in the order of $60 \%$. This implies that the incorporation of $\mathrm{Ho}^{3+}$ dopant state within the band-gap of the $\mathrm{ZnO}$ matrix has enhanced the transparency of the material. However, the transmittance was dropped after incorporation of $0.75 \mathrm{~mol} \% \mathrm{Ho}^{3+}$ defects 
owing to the segregation of the dopant. The optical band-gap (Figure $4 \mathrm{~b}$ ) was extrapolated using the Tauc's formula [35]:

$$
\alpha(x) h v=A\left(h v-E_{g}\right)^{\frac{1}{2}}
$$

where $A$ is the constant, $h v$ is the photon energy, $E_{g}$ the optical band-gap, and $\alpha(x)$ is the absorption coefficient of $\mathrm{ZnO}$ nanoparticle. The absorption coefficient can be calculated from the Beer-Lambert law:

$$
\alpha(x)=-\frac{1}{d} \ln (T)
$$

where $T$ is the normalized transmittance. The band-gaps were obtained from the Tauc plot depicted in Figure $4 \mathrm{~b}$. The extrapolation revealed optical band-gaps of 3.35, 3.34, 3.36 and $3.33 \mathrm{eV}$ corresponding to un-doped $\mathrm{ZnO}, 0.25,0.5$ and $0.75 \mathrm{~mol}^{\circ} \mathrm{Ho}^{3+}$-doped $\mathrm{ZnO}$, respectively. These obtained band-gaps values are in good agreement with previous reports [36].
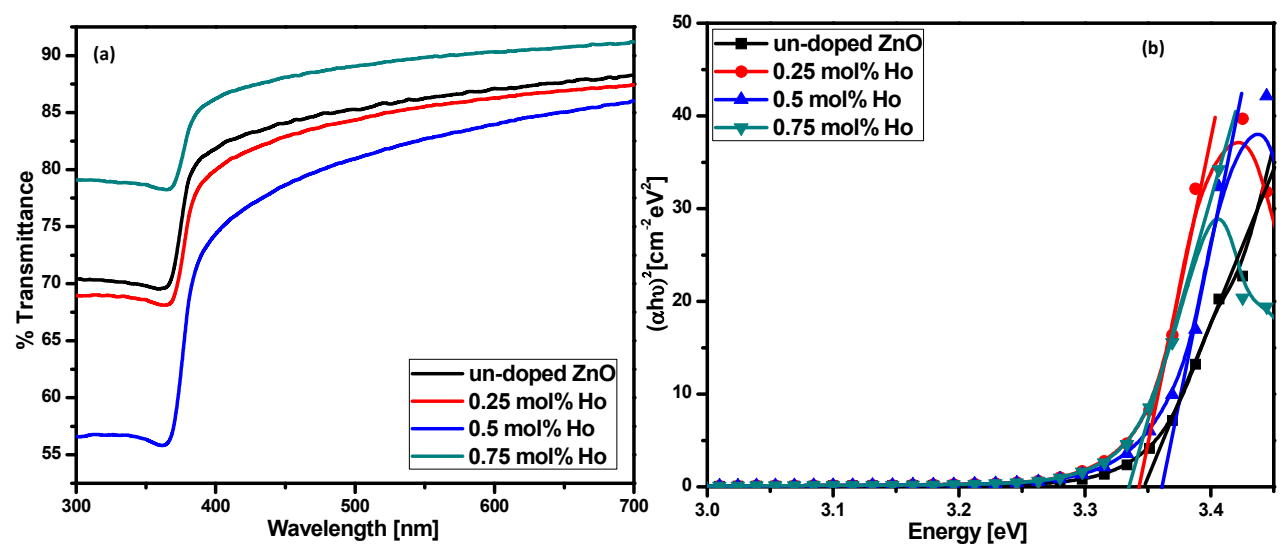

Figure 4. (a) UV-VIS transmission spectra for un-doped and $\mathrm{Ho}^{3+}$-doped $\mathrm{ZnO}$ nanostructures (b) optical band-gap extrapolation from Tauc plot.

Based on the previous characterization, the emission spectrum of the as-synthesized $0.5 \mathrm{~mol} \% \mathrm{Ho}^{3+}$-doped $\mathrm{ZnOnano-phosphor} \mathrm{sample} \mathrm{was} \mathrm{first} \mathrm{examined} \mathrm{by} \mathrm{exciting} \mathrm{with}$ $325 \mathrm{~nm}$ electromagnetic radiations using a xenon lamp. It was found that $\mathrm{Ho}^{3+}(0.5 \mathrm{~mol} \%)$ doped sample exhibited the optimum emission intensity. Figure 5a compares the PL spectra for both un-doped and $0.5 \mathrm{~mol} \% \mathrm{Ho}^{3+}$-doped $\mathrm{ZnO}$ samples using $325 \mathrm{~nm}(3.82 \mathrm{eV}) \mathrm{UV}$ light radiations for excitation. The most common reported $\mathrm{ZnO}$ defects emission trend was observed, and the exciton emission owing to the recombination of electron-hole pairs was also detected at $381 \mathrm{~nm}(3.25 \mathrm{eV})$ for the un-doped $\mathrm{ZnO}$ sample, while $379 \mathrm{~nm}(3.27 \mathrm{eV})$ was observed in the case of $0.5 \mathrm{~mol} \% \mathrm{Ho}^{3+}$-doped $\mathrm{ZnO}$ [37]. It is worth noting that after doping with $\mathrm{Ho}^{3+}$ ions, the free-exciton emission in the $\mathrm{ZnO}$ matrix undergoes two different kinds of modifications. The major alteration observed in the free-exciton emission was the slight blue shift $(2 \mathrm{~nm})$ observed to be derived from $\mathrm{Ho}^{3+}$ doping in the $\mathrm{ZnO}$ matrix as compared to un-doped $\mathrm{ZnO}$, and this shift implies a change in the band structure [38-40] (see Figure 5b). Elilarassi et al. [41] elaborated on such phenomenon, which was assigned to a decrease of the transition probability taking place within the band-gap of the doped $\mathrm{ZnO}$ matrix among the oxygen vacancy and the $\mathrm{Zn}$ vacancy after the substitution of $\mathrm{Zn}^{2+}$ ions by the dopant in the host lattice $[39,40]$. The second modification observed was the severe increase in intensity of the free-exciton emission observed with holmium doping, which was attributed to energy transfer from the $\mathrm{Ho}^{3+}$ ions to $\mathrm{ZnO}$ host and/or to the reduction in concentration of oxygen defects as reported in our previous study [14]. The observed enhancements of the exciton emission confirmed the ability of spontaneous lasing action in the ultraviolet spectral range, thus, positioning $0.5 \mathrm{~mol} \% \mathrm{Ho}^{3+}$-doped $\mathrm{ZnO}$ nanostructures as a candidate material for spintronic applications (see Figure 5a) [42,43]. 
Considering the current extensive controversies about the origin of the visible emission in $\mathrm{ZnO}$, one can speculate on the defects that caused this emission [44]. A change in surface defect occurring on the surface of $\mathrm{ZnO}$ owing to $\mathrm{Ho}^{3+}$ doping could be the main factor causing the blue shift observed in the visible emission. Furthermore, the doping with holmium has occasioned band bending at the surface of $\mathrm{ZnO}$ resulting from the change of the Fermi energy level [45-47]. It is however important to undertake further investigation to elucidate this hypothesis.

Moreover, the $\mathrm{ZnO}: \mathrm{Ho}^{3+}(0.5 \mathrm{~mol} \%)$ emission and excitation spectra are depicted in Figure 5c,d. Five prominent excitation peaks at 383, 397, 439, 467 and 492 nm were observed from the spectrum. From these excitation wavelengths, we have selected the $492 \mathrm{~nm}$ wavelength to measure the emission spectrum of $0.5 \mathrm{~mol}^{\%} \mathrm{Ho}^{3+}$-doped $\mathrm{ZnO}$. A number of emission bands are detected spreading from the visible to the near infrared (NIR) regions at $540\left({ }^{5} \mathrm{~S}_{2},{ }^{5} \mathrm{~F}_{4} \rightarrow{ }^{5} \mathrm{I}_{8}\right), 606\left({ }^{5} \mathrm{~F}_{5} \rightarrow{ }^{5} \mathrm{I}_{8}\right), 670\left({ }^{5} \mathrm{~F}_{5} \rightarrow{ }^{4} \mathrm{I}_{8}\right), 757\left({ }^{5} \mathrm{~S}_{2},{ }^{5} \mathrm{~F}_{4} \rightarrow{ }^{5} \mathrm{I}_{7}\right)$ and 808 $\left({ }^{5} \mathrm{I}_{5} \rightarrow{ }^{5} \mathrm{I}_{8}\right) \mathrm{nm}$ (Figure 5d) [48-52]. The most prominent emission is observed in the green region centered at $540 \mathrm{~nm}$ with a less intense peak at about $574 \mathrm{~nm}$; both peaks aredue to the hypersensitive $\left({ }^{5} \mathrm{~S}_{2},{ }^{5} \mathrm{~F}_{4} \rightarrow{ }^{5} \mathrm{I}_{8}\right)$ transition.
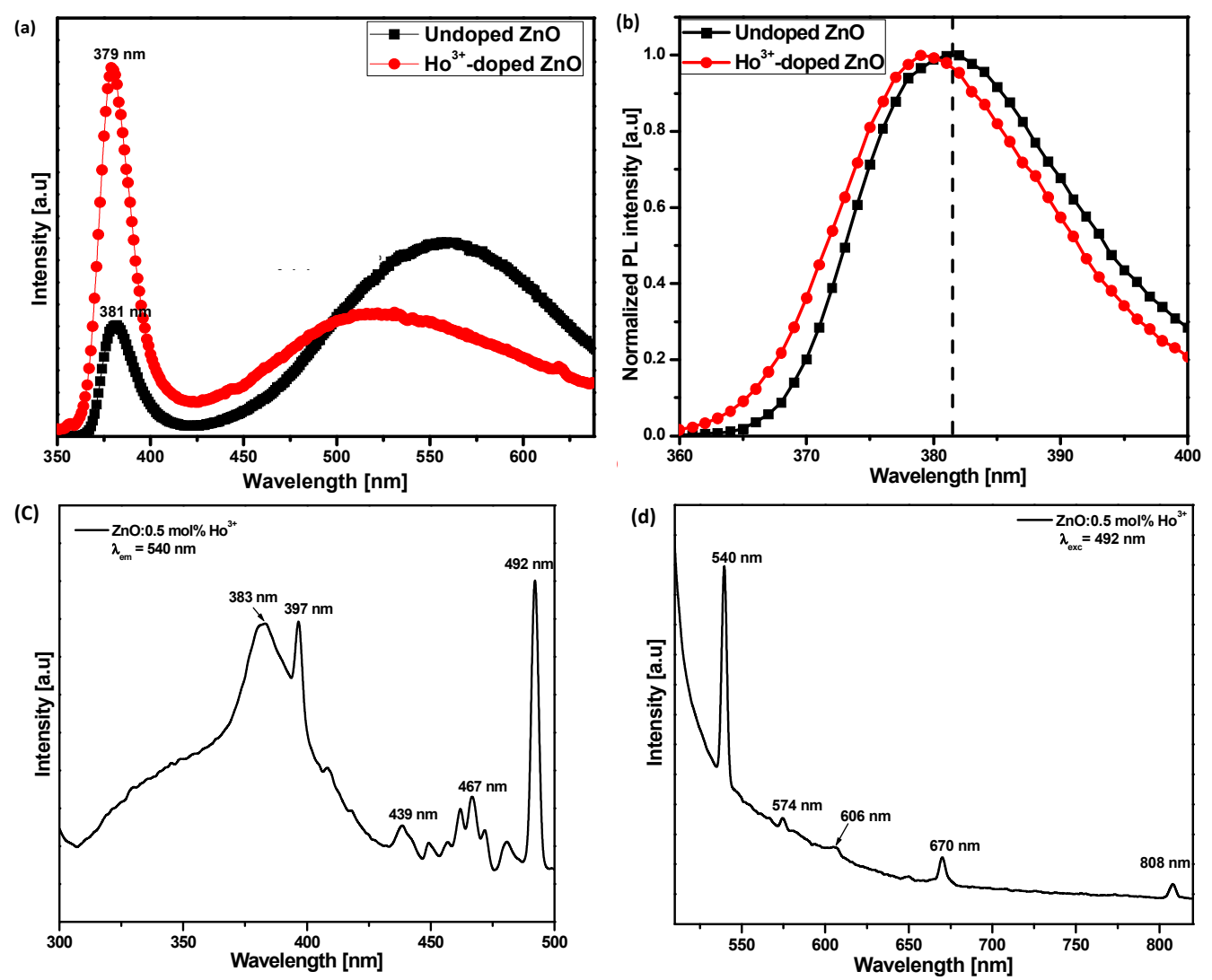

Figure 5. (a) Emission spectra for as prepared un-doped and $0.5 \mathrm{~mol} \% \mathrm{Ho}^{3+}$-doped $\mathrm{ZnO}$ samples $\left(\lambda_{\mathrm{exc}}=325 \mathrm{~nm}\right)$, (b) shows the magnification of the normalized exciton emission peak. (c) Excitation and (d) emission spectra for $0.5 \mathrm{~mol}^{\%} \mathrm{Ho}^{3+}$-doped $\mathrm{ZnO}$ nanocrystals.

\subsection{Surface State XPS Characterization}

Figure 6 shows the XPS spectra for both un-doped and $0.5 \mathrm{~mol} \%$ Ho-doped samples, which allow the elucidation of the oxidation state of different species present in the asprepared nanostructures, namely, Zinc, Oxygen and Holmium. The survey scans (not presented here) for both samples were identical at the sole exclusion of Ho4d core level present in the $\mathrm{Ho}^{3+}$-doped $\mathrm{ZnO}$ samples. Besides $\mathrm{Zn} 2 \mathrm{p}, \mathrm{O}$ 1s, and Ho $4 \mathrm{~d}$ core levels, a C 1s core level arising from extrinsic surface impurities was also detected. The binding energy correction was applied using the C $1 \mathrm{~s}(284.8 \mathrm{eV})$ core level. For both samples, the Zn 2p 
core level which appears as a doublet due to the interaction of the spin and orbital magnetic moments did not encounter any peak shift (not shown here). This observation implies that zinc is not sparingly sensitive to a change in the oxidation state [53]. The de-convoluted $\mathrm{O} 1 \mathrm{~s}$ core level for $(0.5 \mathrm{~mol} \%) \mathrm{Ho}^{3+}$-doped sample (see Figure 6) exhibited three oxygen components. The peaks appeared at $529.21 \pm 0.05,530.32 \pm 0.05$ and $531.27 \pm 0.05 \mathrm{eV}$ ascribed to $\mathrm{O}^{2-}$ ions on the hexagonal wurtzite structure of $\mathrm{ZnO} ; \mathrm{O}^{2-}$ ions in oxygen deficient regions within the $\mathrm{ZnO}$ matrix and chemisorbed species on the surface of $\mathrm{ZnO}$, respectively, were observed [10]. As compared to the un-doped sample, the intensity of the $\mathrm{O}_{2}$ peak was found to decrease owing to a decrease in concentration of oxygen defects in the $0.5 \mathrm{~mol} \% \mathrm{Ho}^{3+}$-doped $\mathrm{ZnO}$ sample. This finding has a direct implication in the luminescence quenching of the green emission observed in the PL spectra, which was also demonstrated in our previous report [14] and similarly by Kumar et al. [54].However, the surface cleaning with $\mathrm{Ar}^{+}$sputtering has an influence on the intensity of $\mathrm{O}_{3}$ peak, which is slightly decreased as compared to the peak before $\mathrm{Ar}^{+}$cleaning. Furthermore, it is important to focus on the detection of Ho $4 \mathrm{~d}$ core level peak at about $160.09 \pm 0.05 \mathrm{eV}$ binding energy (Figure 6e) [55]. The Ho $4 \mathrm{~d}$ core level was de-convoluted and displayed two bands at about $161.04 \pm 0.05 \mathrm{eV}$ and $163.93 \pm 0.05 \mathrm{eV}$ before $\mathrm{Ar}^{+}$sputtering. It is worth noting that the small shoulder appearing at about $175 \mathrm{eV}$ could be assigned to multiplets splitting.
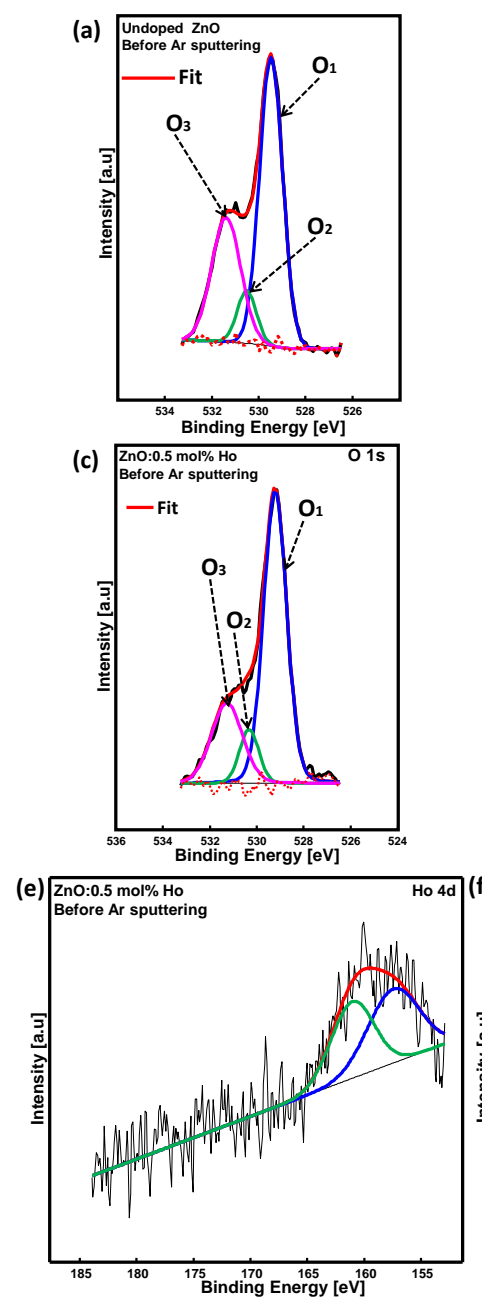

(b)
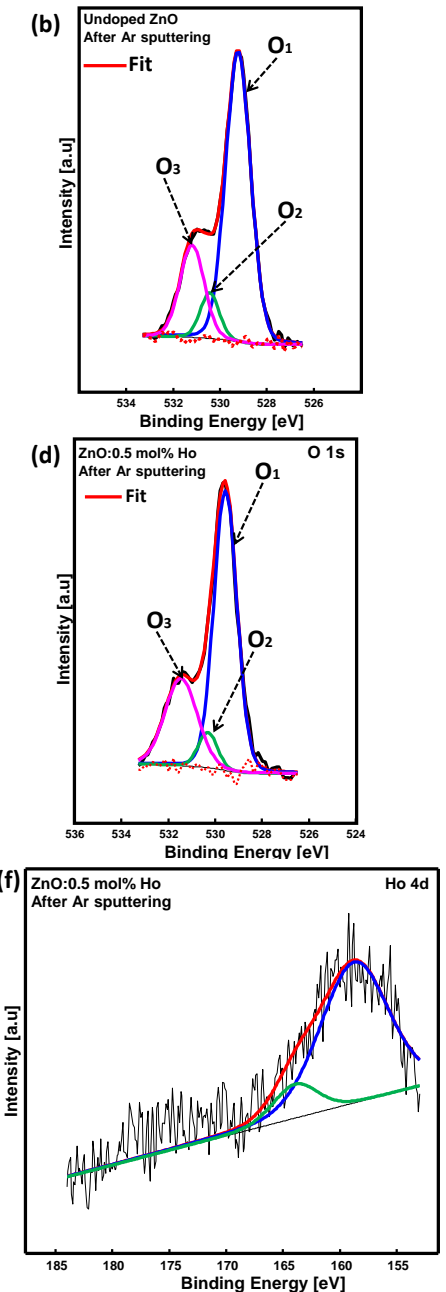

Figure 6. XPS O 1s core levels spectra for un-doped $\mathrm{ZnO}(\mathbf{a})$ before and (b) after $\mathrm{Ar}^{+}$sputtering and $0.5 \mathrm{~mol} \% \mathrm{Ho}^{3+}$-doped $\mathrm{ZnO}(\mathbf{c})$ before and (d) after $\mathrm{Ar}^{+}$sputtering. XPS Ho $4 \mathrm{~d}$ core levels (e) before and (f) after $\mathrm{Ar}^{+}$sputtering. 


\subsection{Room Temperature Ferromagnetic (RT FM) Properties}

Being one of the most reliable spectroscopic techniques to probe defects at the surface and interface of materials, the ESR technique was used in the current study. $\mathrm{ZnO}$ is naturally diamagnetic even though there is still a controversial debate on the matter among scientists [56,57]. However, most scientific reports admitted the probability to observe two types of paramagnetic behaviour in $\mathrm{ZnO}$. The low-field signal often assigned to unpaired electron trapped at an oxygen vacancy site $(\mathrm{g}=2.0023)$ and the high-field signal owing to shallow donor centers $(g=1.96)$ [58]. The spectroscopic g-factor of the free electron can be calculated from the following equation:

$$
\mathrm{g}=\frac{h v}{\beta \mathrm{B}}
$$

where $v$ is the microwave frequency, $h$ is Planck's constant, $\beta$ is the Bohr magneton, and B is the magnetic field.

The investigation of the magnetic behavior of $\mathrm{Ho}^{3+}$-doped $\mathrm{ZnO}$ nanostructures was successfully undertaken in this study. Due to the high sensitivity of the technique to defects, we conducted measurements on various concentrations in order to completely understand the effect of the doping concentration on the number of spins. It is a well-known fact that a number of non-magnetic materials have been observed to exhibit ferromagnetic properties at the nanoscale [10,59-63]. Scientists worldwide have found interest in investigating the RT-FM in un-doped and $\mathrm{Ho}^{3+}$-doped $\mathrm{ZnO}$ nanostructures [64,65]. It is worth mentioning that the $4 f$ rare earth elements exhibit exceptional magnetic properties as compared to the $4 d$ transition metal (TM) elements [66,67]. However, few studies reported the RT-FM of $\mathrm{Ho}^{3+}$ into $\mathrm{ZnO}[68-71]$. At first sight, the ESR results obtained in the current investigation seem not to correlate well with the PL due to the fact that the $\mathrm{Ho}^{3+}$ doping into $\mathrm{ZnO}$ have induced a change in the nature of defects within the matrix. A similar trend was previously reported by Garcia et al. [72] who investigated the $d^{0}$ ferromagnetism in $\mathrm{ZnO}$ capped with organic molecules. He hypothesized that the organic species present in $\mathrm{ZnO}$ samples could induce ferromagnetic-like behaviour (see Figure 7).

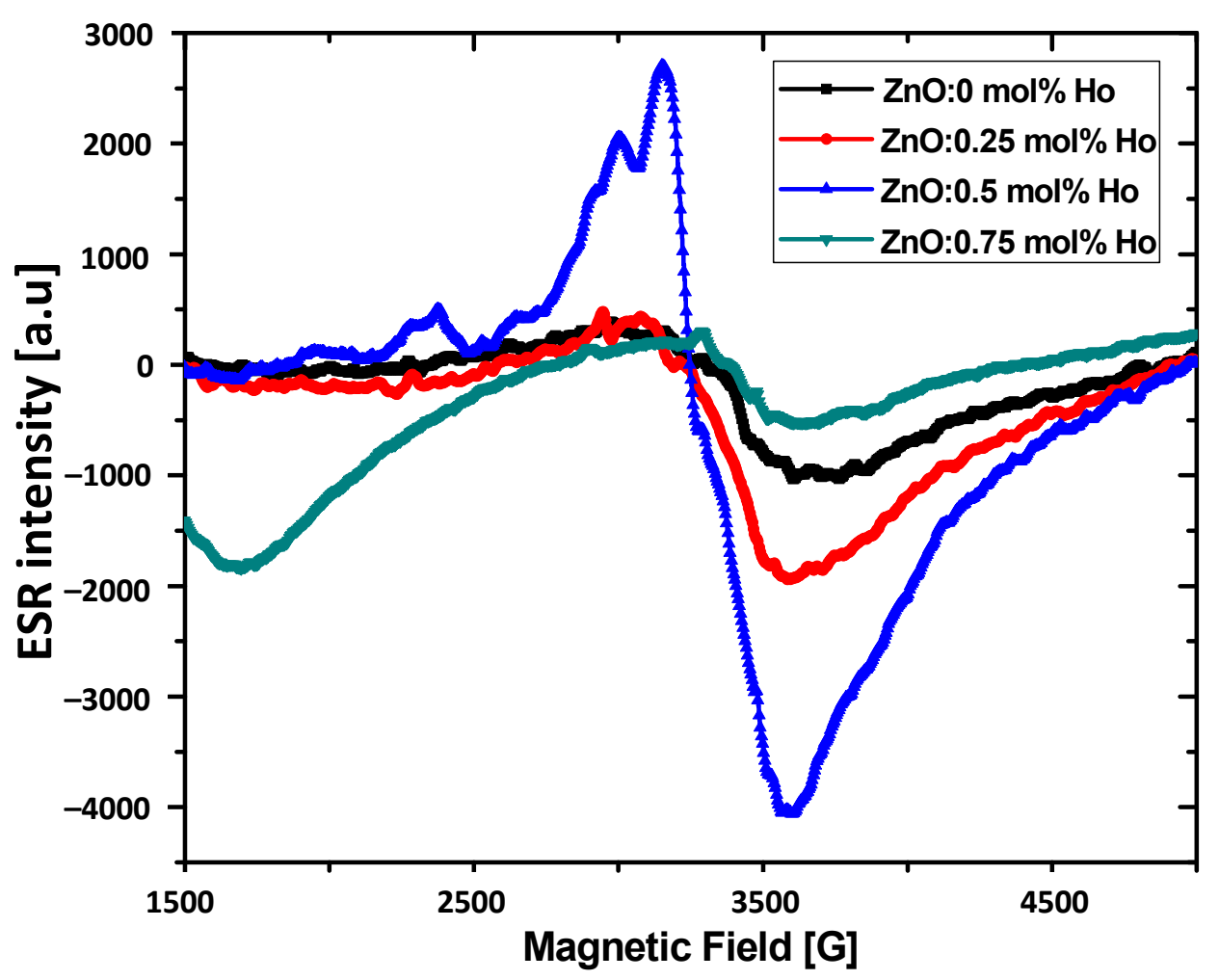

Figure 7. X-band $(9.4 \mathrm{GHz})$ ESR spectra for un-doped and $\mathrm{Ho}^{3+}$-doped $\mathrm{ZnO}$ samples at room temperature. 
In spite of an abundant literature on the study of the RT-FM mechanism in $\mathrm{ZnO}$ nanostructures, the debate on its origin is still open and promising. Xiaoyong $\mathrm{Xu}$ et al. [73] have reported on the size dependence RT-FM in ZnO quantum dots; in their study they established a correlation between the RT-PL and the RT-FM in un-doped $\mathrm{ZnO}$ nanoparticles, denoting that the $d^{0}$ ferromagnetism is largely related to the concentration of native defects such as oxygen vacancy in the samples. However, contrary to previous studies on un-doped $\mathrm{ZnO}$, the doping with $\mathrm{Ho}^{3+}$ could be responsible for the magnetic intensity enhancement observed in this study which is not in accordance with the correlated PL/FM results reported elsewhere [73,74]. This observation is probably due to the important magnetic moment of the $\mathrm{Ho}^{3+}$ ions dopants, which effectively dominated on the RT-FM as compared to the concentration of oxygen defects. From the current observation and based on previous studies, we can speculate on the strong RT-FM observed in the $\mathrm{Ho}^{3+}$-doped samples which could be ascribed to the $s-f$ coupling between the $\mathrm{ZnO}$ host and the $\mathrm{Ho}^{3+}$ dopant due to its large magnetic moment and the incorporation of more ferromagnetic defects within the $\mathrm{ZnO}$ matrix $[63,64,66,75]$. The collected ESR spectra revealed the occurrence of strong microwave absorption at about 3248 Gauss which may be assigned to unpaired electron trapped at an oxygen vacancy site. The obtained g-factor values corresponding to the ferromagnetic resonance of the un-doped and $0.5 \mathrm{~mol} \% \mathrm{Ho}^{3+}$-doped $\mathrm{ZnO}$ were found to be 2.032 and 2.067, respectively. Moreover, the $0.5 \mathrm{~mol} \% \mathrm{Ho}^{3+}$-doped $\mathrm{ZnO}$ sample exhibited an additional peak at about $3004 \mathrm{G}(\mathrm{g}=2.24)$ and $2372 \mathrm{G}(\mathrm{g}=2.83)$ whose features may originate from $\mathrm{Ho}^{3+}$. On the other hand, the peak-to-peak line widths $(\Delta H)$ obtained were found to be $633,648,417$ and $347 \mathrm{G}$ for un-doped $0.25,0.5$ and $0.75 \mathrm{~mol} \%$ $\mathrm{Ho}^{3+}$-doped samples, respectively. Furthermore, the number of spins $\left(N_{s}\right)$ contributing to the ferromagnetic resonance was found to be $1.576 \times 10^{8}, 2.906 \times 10^{8}, 3.35 \times 10^{8}$ and $0.284 \times 10^{8}$ for the $0,0.25,0.5$ and $0.75 \mathrm{~mol}^{\%} \mathrm{Ho}^{3+}$ samples, respectively (see Figure 8 ). It is worth mentioning that the observed enhanced ferromagnetism is related to the number of spins participating in the ferromagnetism and further related to the concentration of $\mathrm{Ho}^{3+}$ [64]. In fact, the maximum microwave absorption intensity was attained at the critical concentration of $0.5 \mathrm{~mol} \%$; above this concentration, a severe decrease was observed (see Figure 7). This observation could be attributed to the ferromagnetism saturation due to excess of holmium ions being segregated on the surface of the $\mathrm{ZnO}$ host matrix. ESR spectra of $\mathrm{Ho}^{3+}$-doped $\mathrm{ZnO}$ samples showed a similar intensity trend as compared to the UV-VIS transmittance spectra.

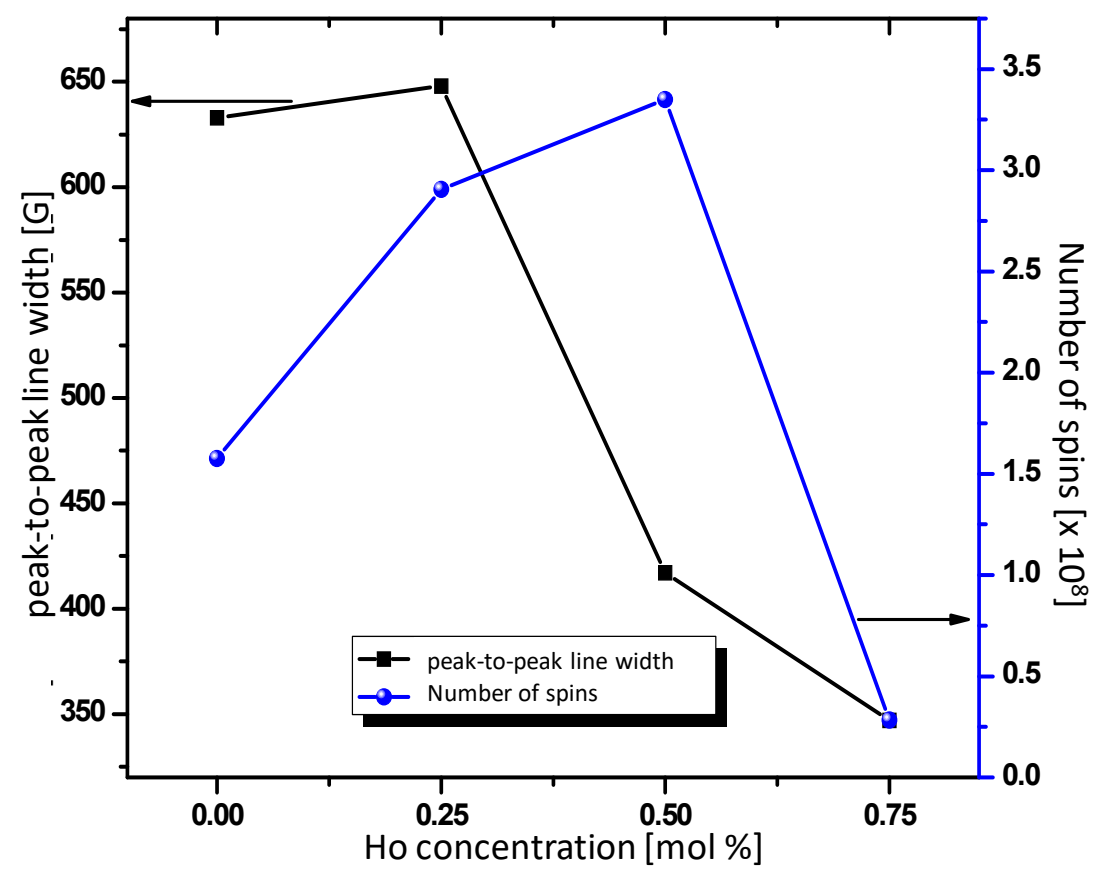

Figure 8. Peak-to-peak line width and number of spins as a function of $\mathrm{Ho}^{3+}$ concentration. 


\subsection{Time-Resolved Photoluminescence Lifetime Analysis}

Time-resolved photoluminescence (TRPL) decay analysis of un-doped and $0.5 \mathrm{~mol} \%$ $\mathrm{Ho}^{3+}$-doped $\mathrm{ZnO}$ samples, which focused on the exciton $(380 \mathrm{~nm})$ and defect $(520 \mathrm{~nm})$ emission is depicted in Figure $9 \mathrm{a}-\mathrm{d}$, and the related fitted parameters are presented in Table 2. The TRPL data collected were analyzedusing multiple exponential functions in DAS-6 software platform. The obtained TRPL decays were found to be non-exponential, meaning that several emissive states were present in all TRPL data with the exception of $\mathrm{ZnO}: \mathrm{Ho}^{3+}(0.5 \mathrm{~mol} \%)$ data which exhibited exponential behaviour at $380 \mathrm{~nm}$ (Figure 9c). The decay profile of $\mathrm{ZnO}$ exciton $(380 \mathrm{~nm}$ ) has been previously reported to contain two emissive states, a fast and slow component [76-79]. The fast decay component $\left(\tau_{1}\right)$ has been assigned to non-radiative de-activation, and the slowdecaytrace $\left(\tau_{2}\right)$ resulted from radiative lifetime of free-excitons [79]. However, in the case of $\mathrm{ZnO}$ defect emission $(520 \mathrm{~nm})$, the faster decay trace $\left(\tau_{1}\right)$ has been assigned to arise from (i) radiative recombination of shallowly trapped electrons and deep trapped holes and (ii) the recombination of donor acceptor pair [77].

Moreover, due to the non-exponential nature of the TRPL decays under investigation, a bi- and tri-exponential function were the most reasonable approach to fit the data using the model presented equation below:

$$
I(t)=I_{0} \sum_{i=1}^{n} A_{i} e^{-\left(\frac{\mathrm{t}}{\tau_{i}}\right)}
$$

where $I(t)$ is the fluorescence intensity at time $t, I_{0}$ is the initial fluorescence intensity, $\tau_{i}$ are lifetimes, and $A_{i}$ are pre-exponential factors.
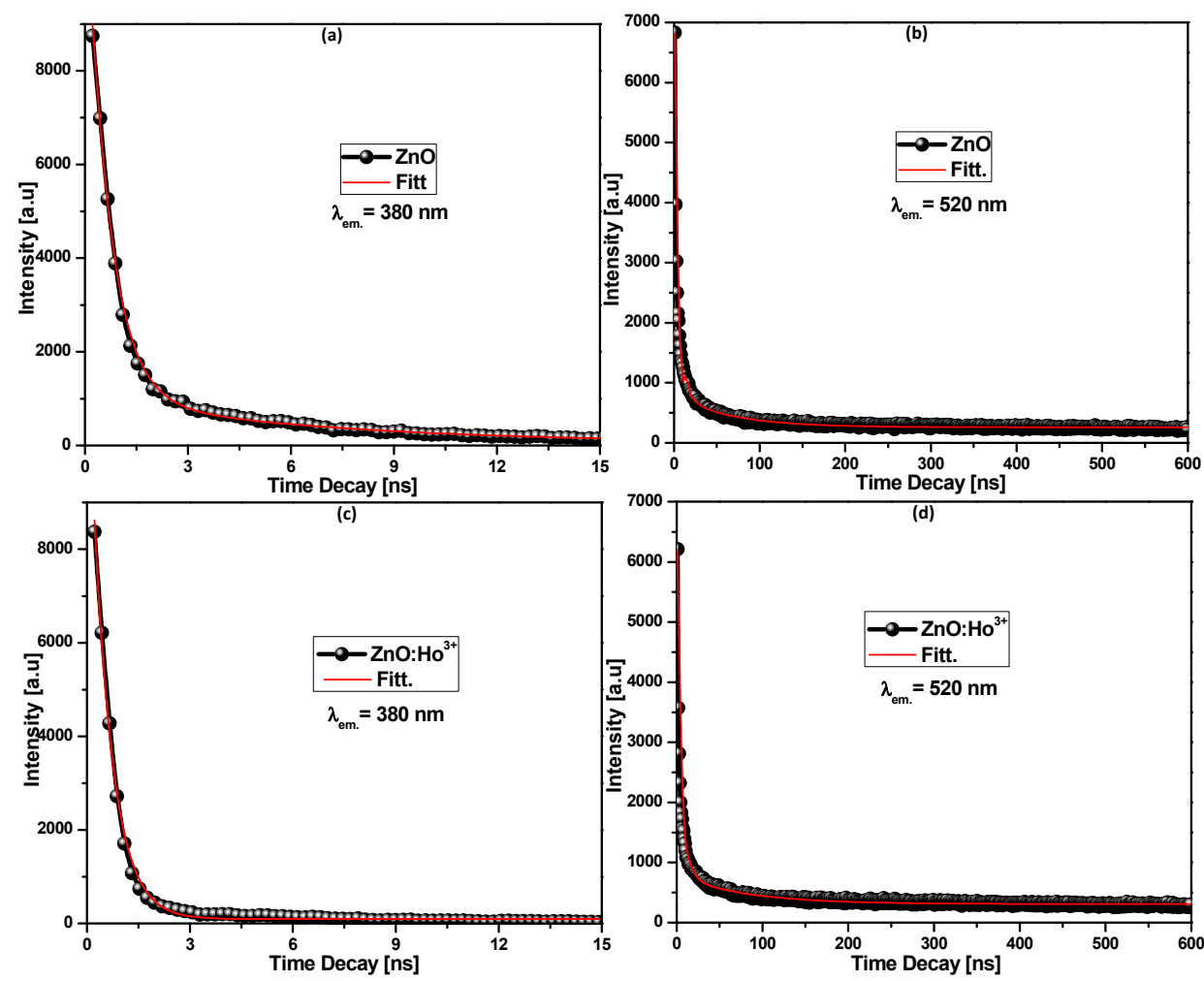

Figure 9. Exciton and defects TRPL lifetime decay of $(\mathbf{a}, \mathbf{b}) \mathrm{ZnO}$ and $(\mathbf{c}, \mathbf{d}) \mathrm{ZnO}: \mathrm{Ho}^{3+}(0.5 \mathrm{~mol} \%)$ nanostructures.

By monitoring the emission at $380 \mathrm{~nm}(3.26 \mathrm{eV})$, it has been observed that the complete de-activation was achieved in about $15 \mathrm{~ns}$, indicating the fast decay of the free-exciton transition. On the other hand, the $520 \mathrm{~nm}(2.38 \mathrm{eV})$ emission revealed the occurrence of 
a much longer decay due to the dominance of deep traps kind of defects. However, for both un-doped and $0.5 \mathrm{~mol} \% \mathrm{Ho}^{3+}$-doped samples, the best fit revealed the existence of three emissive states at $520 \mathrm{~nm}$ Table 2a,b. It is worth noting that the averaged slow decay observed in un-doped $\mathrm{ZnO}$ defect emission results from more efficient trapping of the charge carriers due to high density of defects [77].

Interestingly, the decay profile of the $\mathrm{ZnO}: \mathrm{Ho}^{3+}(0.5 \mathrm{~mol} \%)$ at $380 \mathrm{~nm}$ exhibited a single emissive state much faster than that of un-doped $\mathrm{ZnO}$ which contained two emissive states. This could be the result of the distortion in the band-structure induced by $\mathrm{Ho}^{3+}$ ions doping. Moreover, we can speculate on the behaviour of the slow decay observed in the TRPL at $380 \mathrm{~nm}$, which completely vanishes, this phenomenon is indicative of an energy transfer from the $\mathrm{ZnO}$ exciton to $\mathrm{Ho}^{3+}$ [79]. This result is in accordance with the photoluminescence results reported earlier in this study. Finally, the longer decay of $\left(\tau_{1}\right)$ observed in the doped sample indicates the good optical quality of $\mathrm{ZnO}: \mathrm{Ho}^{3+}(0.5 \mathrm{~mol} \%)$ as compared to the un-doped $\mathrm{ZnO}$ sample.

Table 2. (a) PL Decay of $\mathrm{ZnO}$ nanocrystals dispersed in ethanol under $\lambda_{\mathrm{ex}}=320 \mathrm{~nm}$ using NanoLED. (b) PL Decay of $\mathrm{ZnO}: \mathrm{Ho}^{3+}(0.5 \mathrm{~mol} \%)$ nanostructures dispersed in ethanol under $\lambda_{\text {ex. }}=320 \mathrm{~nm}$ using NanoLED.

\begin{tabular}{ccccc}
\hline \multicolumn{5}{c}{$(\mathbf{a})$} \\
\hline$\lambda_{\mathrm{em} .}(\mathrm{nm})$ & $\tau_{1}(\mathrm{~ns})$ & $\tau_{2}(\mathrm{~ns})$ & $\tau_{3}(\mathrm{~ns})$ & $\chi^{2}$ \\
\hline 380 & 0.651 & 6.769 & - & 0.99 \\
\hline 520 & 0.828 & 7.085 & 65.257 & 0.99 \\
\hline$\lambda_{\mathrm{em} .}(\mathrm{nm})$ & & $(\mathbf{b})$ & & \\
\hline 380 & $\tau_{1}(\mathrm{~ns})$ & $\tau_{2}(\mathrm{~ns})$ & $\tau_{3}(\mathrm{~ns})$ & $\chi^{2}$ \\
\hline 520 & 0.566 & - & - & 0.99 \\
\hline
\end{tabular}

\section{Conclusions}

In summary, the use of the sol-gel method allows facile successful synthesis of $\mathrm{Ho}^{3+}$ doped $\mathrm{ZnO}(0.5 \mathrm{~mol} \%)$ nanocrystals in which the $\mathrm{Ho}^{3+}$ ions were found to be emissive through the $4 f-4 f$ electronic transitions. Holmium was actively emissive at about 540 $\left({ }^{5} \mathrm{~S}_{2},{ }^{5} \mathrm{~F}_{4} \rightarrow{ }^{5} \mathrm{I}_{8}\right), 574,606,670\left({ }^{5} \mathrm{~F}_{5} \rightarrow{ }^{4} \mathrm{I}_{8}\right)$ and $808 \mathrm{~nm}$ allied with the respective intra-ionic transitions. Moreover, optimal $0.5 \mathrm{~mol} \% \mathrm{Ho}^{3+}$ incorporation in $\mathrm{ZnO}$ relatively increased the crystallite size from 4 to $8 \mathrm{~nm}$, tuned the band-gap and modified the initial morphology of un-doped $\mathrm{ZnO}$ spherical-like to rods-like which was attributed to Ostwald ripening effect. Furthermore, enhanced room temperature ferromagnestism related to the number of spins participating to the ferromagnetic resonance was reported. Finally, Time-resolved photoluminescence analysis revealed the change induced in the relaxation charge carriers in defects states as a result of $0.5 \mathrm{~mol} \% \mathrm{Ho}^{3+}$ doping in $\mathrm{ZnO}$.

Supplementary Materials: The following are available online at https:/ /www.mdpi.com/article/10 .3390 / nano11102611/s1, Figure S1: SEM image used to conduct EDS mapping, Figure S2: HRTEM images for (A) un-doped and (B) $(0.5 \mathrm{~mol} \%) \mathrm{Ho}^{3+}$-doped $\mathrm{ZnO}$ nanocrystals.

Author Contributions: G.L.K. was responsible for the concept, methodology and experiments of the study as well as for writing the manuscript. G.H.M. supported the methodology development and contributed to the writing of the manuscript. M.S.D. supported the concept development and design of the experiment. M.S.D. provided funding and contributed to the writing of the manuscript. All authors have read and agreed to the published version of the manuscript.

Funding: G.L.K. is thankful to the University of South Africa for its generous Post-Doctoral Fellowship. This work was supported by the National Research Foundation of South Africa under grant \# 88028 , and by the CSIR. 
Data Availability Statement: Data is contained within the article or Supplementary Material.

Acknowledgments: The authors are grateful to the CSIR and National Research Foundation (NRF) for their financial grant (\# 88028). The National Nano Surface Characterization Facility of the University of the Free State is acknowledged for XPS measurements. The funding support from the University of South Africa (UNISA) is gratefully acknowledged. S.S. Nkosi is acknowledged for ESR measurements.

Conflicts of Interest: The authors declare no conflict of interest.

\section{References}

1. Wojnarowicz, J.; Chudoba, T.; Lojkowski, W. A Review of Microwave Synthesis of Zinc Oxide Nanomaterials: Reactants, Process Parameters and Morphologies. Nanomaterials 2020, 10, 1086. [CrossRef] [PubMed]

2. Özgür, Ü.; Alivov, Y.I.; Liu, C.; Teke, A.; Reshchikov, M.A.; Doğan, S.; Avrutin, V.; Cho, S.J.; Morkoç, H. A comprehensive review of ZnO materials and devices. J. Appl. Phys. 2005, 98, 041301. [CrossRef]

3. Ohno, H. Making nonmagnetic semiconductors ferromagnetic. Science 1998, 281, 951. [CrossRef] [PubMed]

4. Venkatesan, M.; Fitzgerald, C.B.; Lunney, J.G.; Coey, J.M.D. Anisotropic ferromagnetism in substituted zinc oxide. Phys. Rev. Lett. 2004, 93, 177206. [CrossRef] [PubMed]

5. Norberg, N.S.; Kittilstved, K.R.; Amonette, J.E.; Kukkadapu, R.K.; Schwartz, D.A.; Gamelin, D.R. Synthesis of colloidal Mn² ${ }^{2+}$ ZnO quantum dots and high-TC ferromagnetic nanocrystalline thin films. J. Am. Chem. Soc. 2004, 126, 9387. [CrossRef]

6. Waclawik, E.R.; Chang, J.; Ponzoni, A.; Concina, I.; Zappa, D.; Comini, E.; Motta, N.; Faglia, G.; Sberveglieri, G. Functionalised zinc oxide nanowire gas sensors. Beilstein. J. Nanotechnol. 2012, 3, 368.

7. Gulia, S.; Kakkar, R. ZnO Quantum Dots for Biomedical Applications. Adv. Mater. Lett. 2013, 4, 876. [CrossRef]

8. Kuwabara, T.; Omura, Y.; Yamaguchi, T.; Taima, T.; Kohshin, T.; Higashimine, K.; Vohra, V.; Murata, H. Factors affecting the performance of bifacial inverted polymer solar cells with a thick photoactive layer. J. Phys. Chem. C 2014, 118, 4050. [CrossRef]

9. Yang, R.S.; Qin, Y.; Dai, L.M.; Wang, Z.L. Power generation with laterally packaged piezoelectric fine wires. Nat. Nanotechnol. 2009, 4, 34. [CrossRef]

10. Mhlongo, G.H.; Motaung, D.E.; Nkosi, S.S.; Swart, H.C.; Malgas, G.F.; Hillie, K.T.; Mwakikunga, B.W. Temperature-dependence on the structural, optical, and paramagnetic properties of ZnO nanostructures. Appl. Surf. Sci. 2014, 293, 62. [CrossRef]

11. Motaung, D.E.; Mhlongo, G.H.; Nkosi, S.S.; Malgas, G.F.; Mwakikunga, B.W.; Coetsee, E.; Swart, H.C.; Abdallah, H.M.I.; Moyo, T.; Ray, S.S. Shape-selective dependence of room temperature ferromagnetism induced by hierarchical ZnO nanostructures. ACS Appl. Mater. Interfaces 2014, 6, 8981. [CrossRef]

12. Ahmad, U. Growth of Comb-like ZnO Nanostructures for Dye-sensitized Solar Cells Applications. Nanoscale Res.Lett. 2009, 4, 1004 .

13. Wang, Z.L.; Song, J.H. Piezoelectric nanogenerators based on zinc oxide nanowire arrays. Science 2006, 312, 242. [CrossRef]

14. Kabongo, G.L.; Mhlongo, G.H.; Malwela, T.; Mothudi, B.M.; Hillie, K.T.; Dhlamini, M.S. Microstructural and photoluminescence properties of sol-gel derived $\mathrm{Tb}^{3+}$ doped $\mathrm{ZnO}$ nanocrystals. J. Alloys Compd. 2014, 591, 156-163. [CrossRef]

15. Popa, M.; Pop, L.C.; Schmerber, G.; Bouillet, C.; Ersen, O. Impact of the structural properties of holmium doped ZnO thin films grown by sol-gel method on their optical properties. Appl. Surf. Sci. 2021, 562, 150159. [CrossRef]

16. Aydin, S.; Turgut, G. Synthesis and investigation of some physical properties of pure and Ho-loaded ZnO nano-rods. Appl. Phys. A 2019, 125, 622. [CrossRef]

17. Khataee, A.; Saadi, S.; Vahid, B.; Joo, S.W. Sonochemical synthesis of holmium doped zinc oxide nanoparticles: Characterization, sonocatalysis of reactive orange 29 and kinetic study. J. Ind. Eng. Chem. 2016, 35, 167-176. [CrossRef]

18. Shubra, S.; Divya, D.J.N.; Ramachandran, B.; Ramachandra, R.M.S. Synthesis and comparative study of Ho and Y doped ZnO nanoparticles. Mat. Lett. 2011, 65, 2930-2933.

19. Franco, A., Jr.; Pessoni, H.V.S. Optical band-gap and dielectric behavior in Ho-doped ZnO nanoparticles. Mat. Lett. 2016, 180, 305-308.

20. Kashif, M.; Ali, S.M.U.; Ali, M.E.; Abdoulgafour, H.I.; Hashim, H.; Wilander, M.; Hassan, Z. Morphological, optical, and Raman characteristics of ZnO nanoflakes prepared via a sol-gel method. Phys. Status Solidi A 2012, 209, 143-147. [CrossRef]

21. Kashif, M.; Ali, M.E.; Ali, S.M.U.; Hashim, U. Sol-gel synthesis of Pd doped ZnO nanorods for room temperature hydrogen sensing applications. Ceram. Int. 2013, 34, 6461-6466. [CrossRef]

22. Kabongo, G.L.; Mhlongo, G.H.; Mothudi, B.M.; Mbule, P.S.; Hillie, K.T.; Dhlamini, M.S. Structural, photoluminescence and XPS properties of $\mathrm{Tm}^{3+}$ ions in $\mathrm{ZnO}$ nanostructures. J. Lum. 2017, 187, 141-153. [CrossRef]

23. Kabongo, G.L.; Mbule, P.S.; Mhlongo, G.H.; Mothudi, B.M.; Hillie, K.T.; Dhlamini, M.S. Photoluminescence quenching and enhanced optical conductivity of P3HT-derived Ho ${ }^{3+}$-doped ZnO nanostructures. Nanoscale Res. Lett. 2016, 11, 1-11. [CrossRef]

24. Kabongo, G.L.; Mbule, P.S.; Mhlongo, G.H.; Mothudi, B.M.; Dhlamini, M.S. Time-resolved fluorescence decay and Gaussian analysis of P3HT-derived $\mathrm{Ho}^{3+}$ - and $\mathrm{Tm}^{3+}$-doped $\mathrm{ZnO}$ nanostructures. Bull. Mater. Sci. 2020, 43, 48. [CrossRef]

25. Lifshitz, I.M.; Slyozov, V.V. The kinetics of precipitation from supersaturated solid solutions. J. Phys.Chem. Solids 1961, 19, 35. [CrossRef]

26. Wagner, C. Theorie der Alterung von Niderschlagen durch Umlösen (Ostwald Reifung). Z. Elektrochem. 1961, 65, 581. 
27. Viswanatha, R.; Sarma, D.D. Growth of Nanocrystals in Solution. In Nanomaterials Chemistry: Recent Developments and New Directions; Rao, C.N.R., Müller, A., Cheetham, A.K., Eds.; Wiley-VCH Verlag GmbH \& Co. KgaA: Weinheim, Germany, 2007. [CrossRef]

28. Liao, H.-G.; Cui, L.; Whitela, S.; Zheng, H. Real-time imaging of $\mathrm{Pt}_{3}$ Fe nanorod growth in solution. Science $2012,336,1011$. [CrossRef]

29. Liu, Y.; Lin, X.-M.; Sun, Y.; Rajh, T. Cu-Catalyzed Asymmetric Borylative Cyclization of Cyclohexadienone-Containing 1,6-Enynes. J. Am. Chem. Soc. 2013, 135, 3764. [CrossRef]

30. Layek, A.; Mishra, G.; Sharma, A.; Spasova, M.; Dhar, S.; Chowdhury, A.; Bandyopadhyaya, R. A Generalized Three-Stage Mechanism of ZnO Nanoparticle Formation in Homogeneous Liquid Medium. J. Phys. Chem. C 2012, 116, 24757. [CrossRef]

31. De la Rosa, L.S.; Chavez Portillo, M.; Mora-Ramirez, M.A.; Carranza Tellez, V.; Pacio Castillo, M.; Juarez Santiesteban, H.; Cortes Santiago, A.; Portillo Moreno, O. Synthesis of holmium oxide $\left(\mathrm{Ho}_{2} \mathrm{O}_{3}\right)$ nanocrystal by chemical bath deposition. Optik 2020, 216, 164875. [CrossRef]

32. Patterson, A.L. The Scherrer Formula for X-Ray Paticle size. Phys. Rev. 1939, 56, 978. [CrossRef]

33. Li, X.-H.; Xu, J.-H.; Jin, M.; Shen, H.; Li, X.M. Electrical and optical properties of bulk ZnO single crystal grown by flux Bridgman method. Chin. Phys. Lett. 2006, 23, 3356.

34. Bang, J.; Yang, H.; Holloway, P.H. Enhanced luminescence of $\mathrm{SiO}_{2}$ :Eu ${ }^{3+}$ by energy transfert from $\mathrm{ZnO}$ nanoparticles. J. Chem. Phys. 2005, 123, 084709. [CrossRef] [PubMed]

35. Tauc, J. Optical Properties of Solids; Abeles, F., Ed.; North-Holland Pub. Co.: Amsterdam, The Netherlands, 1972; ISBN 10:0720402042/13:9780720402049.

36. Morkoç, H.; Hadis, Ü.Ö. Zinc Oxide: Fundamentals, Materials and Device Technology; Wiley-VCH Verlag GmbH \& Co., KgaA: Weinheim, Germany, 2009; ISBN 978-3-527-40813-9.

37. Wahab, R.; Hwang, I.H.; Kim, Y.-S.; Musarrat, J.; Siddiqui, M.A.; Seo, H.-K.; Tripathye, S.K.; Shin, H.-S. Non-hydrolytic synthesis and photo-catalytic studies of ZnO nanoparticles. Chem. Eng. J. 2011, 175, 450. [CrossRef]

38. Fox, M.A.; Dulay, M.T. Heterogeneous photocatalysis. Chem. Rev. 1993, 93, 341. [CrossRef]

39. Liu, Y.M.; Fang, Q.Q.; Wu, M.Z.; Li, Y.; Lv, Q.R.; Zhou, J.; Wang, B.M. Structure and photoluminescence of arrayed $\mathrm{Zn}_{1-\mathrm{x}} \mathrm{Co}_{\mathrm{x}} \mathrm{O}$ nanorods grown via hydrothermal method. J. Phys. D Appl. Phys. 2007, 40, 4592.

40. Baiqi, W.; Xudong, S.; Qiang, F.; Iqbal, J.; Yan, L.; Honggang, F.; Dapeng, Y. Photoluminescence properties of Co-doped ZnO nanorods array fabricated by the solution method. Phys. E 2009, 41, 413. [CrossRef]

41. Elilarassi, R.; Chandrasekaran, G. Synthesis and optical properties of Ni-doped zinc oxide nanoparticles for optoelectronic applications. Optoelectron. Lett. 2010, 6, 6. [CrossRef]

42. Mustaqima, M.; Liu, C. ZnO-based nanostructures for dilute magnetic semiconductor. Turk. J. Phys. 2014, 38, 429. [CrossRef]

43. Xian, F.L.; Li, X.Y. Effect of nd doping level on optical and structural properties of $\mathrm{ZnO}$ :Nd thin films synthesized by the sol-gel route. Opt. Laser Technol. 2013, 45, 508. [CrossRef]

44. Zhang, W.; Zhao, J.; Liu, Z.; Liu, Z. Structural, optical and magnetic properties of $\mathrm{Zn}_{1-\mathrm{x}} \mathrm{Fe}_{\mathrm{x}} \mathrm{O}$ powders by sol-gel method. Appl. Surf. Sci. 2013, 284, 49. [CrossRef]

45. Ramani, M.; Ponnusamy, S.; Muthamizhchelvan, C. Zinc oxide nanoparticles: A study of defect level blue-green emission. Opt. Mater. 2012, 34, 817. [CrossRef]

46. Spanhel, L.; Haase, M.; Weller, H.; Henglein, A. Photochemistry of colloidal semiconductors. 20. Surface modification and stability of strong luminescing CdS particles. J. Am.Chem. Soc. 1987, 109, 5649. [CrossRef]

47. Zhang, D.H. Properties of ZnO Films Prepared by Ionbeam Assisted Reactive Deposition and by rf Bias Sputtering. Ph.D. Thesis, University of Waterloo, Waterloo, ON, Canada, 1993.

48. Jean-Claude, G. Bünzli and Anne-Sophie Chauvin. Lanthanides in Solar Energy Conversion. In Handbook on the Physics and Chemistry of Rare Earths; Jean-Claude, G.B., Vitalij, K.P., Eds.; Elsevier: Amsterdam, The Netherlands, 2014; Volume 44, pp. 169-281. ISBN 978-0-444-62711.

49. Bai, Y.; Wang, Y.; Peng, G.; Yang, K.; Zhang, X.; Song, Y. Enhanced upconversion photoluminescence intensity by doping Li ${ }^{+}$in $\mathrm{Ho}^{3+}$ and $\mathrm{Yb}^{3+}$ codoped $\mathrm{Y}_{2} \mathrm{O}_{3}$ nanocrystals. J. Alloys Compd. 2009, 478, 676. [CrossRef]

50. Boyer, J.C.; Vetrone, F.; Capobianco, J.A.; Speghini, A.; Bettinelli, M. Optical transitions and upconversion properties of Ho ${ }^{3+}$ doped $\mathrm{ZnO}-\mathrm{TeO}_{2}$ glass. J. Appl. Phys. 2003, 93, 9460. [CrossRef]

51. Dhlamini, M.S.; Mhlongo, G.H.; Swart, H.C.; Hillie, K.T. Energy transfer between doubly doped $\mathrm{Er}^{3+}, \mathrm{Tm}^{3+}$ and $\mathrm{Ho}^{3+} \mathrm{rare} \mathrm{earth}$ ions in $\mathrm{SiO}_{2}$ nanoparticles. J. Lum. 2011, 131, 790. [CrossRef]

52. Xiushan, Z.; Peyghambarian, N. High-power ZBLAN glass fiber lasers: Review and prospect. Adv. Optoelectron. 2010, 2010, 501956. [CrossRef]

53. Wöll, C. The chemistry and physics of zinc oxide surfaces. Prog. Surf. Sci. 2007, 82, 55. [CrossRef]

54. Kumar, V.; Swart, H.C.; Ntwaeaborwa, O.M.; Kroon, R.E.; Terblans, J.J.; Shaat, S.K.K.; Yousif, A.; Duvenhage, M.M. Origin of the red emission in zin oxide nanophosphors. Mater. Lett. 2013, 101, 57. [CrossRef]

55. Moulder, J.F.; Stickle, W.F.; Sobol, P.E.; Bomben, K.D. Handbook of X-ray Photoelectron Spectroscopy; Perkin-Elmer Corporation: Eden-Prairie, MN, USA, 1992.

56. Gehlhoff, W.; Hoffmann, A. Acceptors in ZnO nanocrystals: A reinterpretation. Appl. Phys. Lett. 2012, 101, 262106. [CrossRef] 
57. Teklemichael, S.T.; Hlaing, O.W.M.; Mc Cluskey, M.D.; Walter, E.D.; Hoyt, D.W. Acceptors in ZnO nanocrystals. Appl. Phys. Lett. 2011, 98, 232112. [CrossRef]

58. Zeng, H.; Duan, G.; Li, Y.; Yang, S.; Xu, X.; Cai, W. Blue luminescence of ZnO nanoparticles based on Non-Equilibrium Processes: Defect Origins and Emission controls. Adv. Funct. Mater. 2010, 20, 561. [CrossRef]

59. Dietl, T.; Ohno, H.; Matsukura, F.; Cibert, J.; Ferrand, D. Zener model description of ferromagnetism in zinc-blende magnetic semiconsuctors. Science 2000, 287, 1019. [CrossRef] [PubMed]

60. Radovanovic, P.V.; Gamelin, D.R. High-temperature ferromagnetism in $\mathrm{Ni}^{2+}$-doped $\mathrm{ZnO}$ aggregates prepared from colloidal dilute magnetic semiconductor quantum dots. Phys. Rev. Lett. 2003, 91, 157202/1. [CrossRef] [PubMed]

61. Schwartz, D.A.; Gamelin, D.R. Reversible $300 \mathrm{~K}$ ferromagnetic ordering in a dilute magnetica semiconductor. Adv. Mater. 2004, 16, 2115. [CrossRef]

62. Baik, J.M.; Lee, J.L. Fabrication of vertically well-alligned ( $\mathrm{Zn}, \mathrm{Mn}) \mathrm{O}$ nanorods with room temperature ferromagnetism. Adv.Mater. 2005, 17, 2745. [CrossRef]

63. Bishnoi, S.; Khichar, N.; Das, R.; Kumar, V.; Kotnala, R.K.; Chawla, S. Triple excitation with dual emission in paramagnetic $\mathrm{ZnO}: \mathrm{Er}^{3+}$ nanocrystals. RSC Adv. 2014, 4, 32726. [CrossRef]

64. Rai, G.M.; Iqbal, M.A.; Xu, Y.; Will, I.G.; Zhang, W. Influence of rare earth $\mathrm{Ho}^{3+}$ doping on structural, microstructure and magnetic properties of $\mathrm{ZnO}$ bulk and thin film systems. Chin. J. Chem. Phys. 2011, 24, 353.

65. Popa, M.; Schmerber, G.; Toloman, D.; Gabor, M.S.; Mesaros, A.; Petrisor, T. Magnetic and electrical properties of undoped and holmium doped $\mathrm{ZnO}$ thin films grown by sol-gel method. In Advanced Engineering Forum; Trans Tech Publications Ltd.: Stafa-Zurich, Switzerland, 2013; Volume 8, pp. 301-308. [CrossRef]

66. Dalpian, G.M.; Wei, S.-H. Electron-induced stabilization of ferromagnetism in $\mathrm{Ga}_{1-\mathrm{x}} \mathrm{Gd}_{\mathrm{x}} \mathrm{N}$. Phys. Rev. B 2005, 72, 115201. [CrossRef]

67. Shi, H.; Zhang, P.; Li, S.-S.; Xia, J.-B. Magnetic coupling properties of rare-earth metals (Gd, Nd) doped ZnO: First-principles calculations. arXiv 2010, arXiv:1005.1115v1. [CrossRef]

68. Chen, Q.; Wang, J. ferromagnetism in Nd-doped $\mathrm{ZnO}$ nanowires and the influence of oxygen vacancies: Ab initio calculations. Phys. Chem. Chem. Phys. 2013, 15, 17793. [CrossRef]

69. Wang, D.D.; Chen, Q.; Xing, G.Z.; Yi, J.B.; Bakaul, S.R.; Ding, J.; Wang, J.L.; Wu, T. Robust room temperature ferromagnetism with Giant anisotropy in Nd-doped ZnO nanowire arrays. Nano Lett. 2012, 12, 3994. [CrossRef] [PubMed]

70. Ungureanu, M.; Schmidt, H.; Xu, Q.Y.; Wenckstern, H.V.; Spemann, D.; Hochmuth, H.; Lorenz, M.; Grundmann, M. Electrical and magnetic properties of RE-doped $\mathrm{ZnO}$ thin films (RE = Gd,Nd). Superlattice Microst. 2007, 42, 231. [CrossRef]

71. Potzger, K.; Zhou, S.Q.; Eichhorn, F.; Helm, M.; Skorupa, W.; Mucklich, A.; Fassbender, J.; Herrmannsdorfer, T.; Bianchi, A. ferromagnetic Gd-implanted ZnO single crystals. J. Appl.Phys. 2006, 99, 063906. [CrossRef]

72. Garcia, M.A.; Merino, J.M.; Pinel, E.F.; Quesada, A.; De la Venta, J.; Ruíz González, M.L.; Castro, G.R.; Crespo, P.; Llopis, J.; González-Calbet, J.M.; et al. Magnetic properties of ZnO nanoparticles. Nano Lett. 2007, 7, 1489. [CrossRef] [PubMed]

73. Xu, X.; Xu, C.; Dai, J.; Hu, J.; Li, F.; Zhang, S. Size dependence Defect-induced room temperature ferromagnetism in undoped ZnO nanoparticles. J. Phys. Chem. C 2012, 116, 8813. [CrossRef]

74. Xing, G.; Wang, D.; Yi, J.; Yang, L.; Gao, M.; He, M.; Yang, J.; Ding, J.; Sum, T.C.; Wu, T. correlated d0 ferromagnetism and photoluminescence in undoped $\mathrm{ZnO}$ nanowires. Appl. Phys. Lett. 2010, 96, 112511. [CrossRef]

75. Dhar, S.; Brandt, O.; Ramsteiner, M.; Sapega, V.F.; Ploog, K.H. colossal magnetic moment of Gd in GaN. Phys. Rev. Lett. 2005, 94, 037205. [CrossRef] [PubMed]

76. Zhong, Y.; Djurisic, A.B.; Hsu, Y.F.; Wong, K.S.; Brauer, G.; Ling, C.C.; Chan, W.K. Exceptionally long exciton photoluminescence lifetime in ZnO tetrapods. J. Phys.Chem. C 2008, 112, 16286. [CrossRef]

77. Layek, A.; Manna, B.; Chowdhury, A. Carrier recombination dynamics through defect states of ZnO nanocrystals: From nanoparticles to nanorods. Chem. Phys. Lett. 2012, 539-540, 133. [CrossRef]

78. Lee, S.-K.; Chen, S.L.; Hongxing, D.; Sun, L.; Chen, Z.; Chen, W.M.; Buyanova, I.A. Long lifetime of free excitons in ZnO tetrapod structures. Appl. Phys. Lett. 2010, 96, 083104. [CrossRef]

79. Guidelli, E.J.; Baffa, O.; Clarke, D.R. Enhanced UV emission from Silver/ZnO and Gold/ZnO Core-Shell nanoparticles: Photoluminescence, radioluminescence, and optically stimulated luminescence. Sci. Rep. 2015, 5, 14004. [CrossRef] 